RELACult - Revista Latino-Americana de Estudos em Cultura e Sociedade e-ISSN 2016/Atual: 2525-7870 | e-ISSN 2015/2016: 2447-018X

\title{
Corpo em Movimento no PIBID/UFPel: uma proposta interdisciplinar na EEEF Dom Joaquim Ferreira de Mello
}

\author{
Body Moving in PIBID / UFPel: an interdisciplinary approach in EEEF \\ Dom Joaquim Ferreira de Mello
}

Cuerpo en movimiento en PIBID / UFPel: un enfoque interdisciplinar en FEEE Dom Joaquim Ferreira de Mello

\author{
Denise Castanha de Avila de Lemos ${ }^{1}$ \\ Maristani Polidori Zamperetti ${ }^{2}$ \\ Juliana Aparecida Fernando ${ }^{3}$ \\ Juliana Boanova Souza 4
}

\begin{abstract}
Resumo
O presente artigo visa apresentar o Projeto Interdisciplinar desenvolvido em 2015, na Escola Estadual de Ensino Fundamental Dom Joaquim Ferreira de Mello, localizada em Pelotas, RS, a partir das atividades planejadas no contexto do PIBID (Programa Institucional de Bolsas de Iniciação à Docência) da Universidade Federal de Pelotas, UFPel. O projeto "Corpo em Movimento - Esporte, Linguagem, Espaço e Saúde" estendeu as possibilidades de aplicação do trabalho para um espaço não pertencente à escola: uma praça próxima às dependências da escola, o Parque Dom Antônio Zattera. Buscando desenvolver o respeito mútuo e companheirismo entre os alunos a partir da prática esportiva interligando saúde, movimento, esportes e percepção das mensagens corporais, o projeto foi desenvolvido em meio às dificuldades escolares, em função das paralisações dos professores estaduais. O contato direto com a realidade escolar brasileira e a convivência com os alunos, professores e com suas respectivas carências, foi uma aprendizagem ressaltada pelo grupo do PIBID.
\end{abstract}

Palavras-Chave: Interação, Interdisciplinaridade, PIBID, Projeto.

Abstract

This article presents the Interdisciplinary Project developed in 2015, at the Elementary School Dom Joaquim Ferreira de Mello, located in Pelotas, from the activities planned in the context of PIBID (Institutional Program Initiation Scholarships to Teaching) of Federal University of Pelotas, UFPel. The "Body in Motion - Sport, Language, Space and Health" held out the job application possibilities for a non belongs to space: a nearby square to the school grounds, the Parque Dom Antonio Zattera. Seeking to develop mutual respect and

\footnotetext{
${ }^{1}$ Acadêmica do Curso de Artes Visuais - Licenciatura, Bolsista do PIBID/UFPEL, Universidade Federal de Pelotas; UFPel, Pelotas, Rio Grande do Sul, Brasil. denlemos@gmail.com

${ }^{2}$ Doutora em Educação; Universidade Federal de Pelotas; UFPel, Pelotas, Rio Grande do Sul, Brasil. maristaniz@hotmail.com.

${ }^{3}$ Doutora em Biologia Vegetal, Universidade Federal de Pelotas; UFPel, Pelotas, Rio Grande do Sul, Brasil. juli_fernando@yahoo.com.br.

4 Acadêmica do Curso de Matemática - Licenciatura, Bolsista do PIBID/UFPEL, Universidade Federal de Pelotas; UFPel, Pelotas, Rio Grande do Sul, Brasil. ju.boanova@bol.com.br.
} 
fellowship among students from the sports practice linking health, movement, sports and perception of bodily messages, the project was developed in the midst of learning difficulties, due to shutdowns of state teachers. Direct contact with the Brazilian school reality and living with students, teachers and their respective needs, it was a learning highlighted by PIBID group.

Keywords: Interaction, Interdisciplinary, PIBID, Project.

\section{Resumen}

En este artículo se presenta el proyecto interdisciplinario desarrolló en el año 2015, en la Escuela Primaria del Estado Dom Joaquim Ferreira de Mello, que se encuentra en Pelotas, a partir de las actividades previstas en el marco de PIBID (Programa Institucional de Iniciación becas para la enseñanza) de Universidad Federal de Pelotas, UFPel. El "Cuerpo en Movimiento - Deporte, Lenguajes, Espacio y Salud" tendió las posibilidades de solicitud de empleo para un no pertenece al espacio: una plaza cercana a las instalaciones de la escuela, el Parque Don Antonio Zattera. Buscando desarrollar el respeto mutuo y el compañerismo entre los estudiantes de la práctica deportiva vinculación de la salud, el movimiento, el deporte y la percepción de los mensajes corporales, el proyecto se desarrolló en medio de las dificultades de aprendizaje, debido a las paradas de los maestros estatales. El contacto directo con la realidad escolar de Brasil y que viven con los estudiantes, los profesores y sus respectivas necesidades, fue un aprendizaje de relieve por grupo PIBID.

Palabras claves: Interacción, Interdisciplinaridad, PIBID, Proyecto.

\section{Introdução}

A Escola Estadual de Ensino Fundamental Dom Joaquim Ferreira de Mello foi fundada em 1944 e situa-se na zona urbana da cidade de Pelotas. No ano de 2015, a falta de acordo entre a Secretaria de Educação e a Cúria Diocesana, proprietária do imóvel, inviabilizou o contrato de aluguel do edifício, obrigando a mudança do educandário para outro endereço, à Rua Professor Doutor Araújo, 1564, Centro, Pelotas/RS.

Atualmente, o desafio enfrentado pela escola é a adequação de suas atividades a um prédio em endereço residencial, sem estrutura física e que comporte suas necessidades: vários cômodos contíguos sem corredor; falta de cozinha de tamanho adequado; salas de aula de tamanho reduzido; ausência de pátio para a prática esportiva.

Portanto, a estrutura física da escola difere do início do projeto PIBID de 2014, o que gerou necessidades de mudança no projeto dimensionado naquele ano. Dessa forma, o grupo PIBID ampliou o tema sugerido a partir do diagnóstico inicial, abordando não somente o esporte, mas também o espaço, a linguagem e a saúde, denominando o projeto de "Corpo em Movimento - Esporte, Linguagem, Espaço e Saúde" estendendo as possibilidades de aplicação do trabalho para um espaço não pertencente à escola, mas sim à comunidade: uma praça próxima às dependências da escola Dom Joaquim Ferreira de Mello, conhecida como Parque Dom Antônio Zattera.

O tema "Corpo em Movimento - Esporte, Linguagem, Espaço e Saúde" propôs-se a desenvolver atividades interdisciplinares que contemplassem o respeito às diferenças, ao 
outro e a si mesmo, o desenvolvimento da autonomia, cooperação e tolerância no ambiente escolar.

A partir do diagnóstico escolar efetuado na EEEF. Dom Joaquim Ferreira de Mello constatou- se por meio de entrevistas e observações realizadas em sala de aula, no horário do recreio e depoimentos de professores da Escola, situações de agressividade verbal, fato que levou à necessidade de evidenciar o respeito e colaboração no ambiente escolar por meio de atividades esportivas e de comunicação. Dessa forma, o projeto abordou o tema esporte e a importância do corpo em movimento como resgate do respeito mútuo, desenvolvendo habilidades, práticas e saberes que contribuam para o autoconhecimento e a autoestima dos alunos.

O objetivo geral previa o desenvolvimento do respeito mútuo e companheirismo entre os alunos a partir da prática esportiva interligando saúde, movimento, esportes e percepção das mensagens corporais. Dentre os objetivos específicos salientamos a valorização do convívio entre os alunos e a importância do trabalho em equipe; o desenvolvimento da prática de um esporte pouco conhecido pelos alunos; o alerta sobre o consumo excessivo de alimentos que não fazem bem a saúde e a importância de uma boa alimentação antes da prática de esportes e o reconhecimento da relevância do movimento e expressão corporal na inter-relação cotidiana, compreendendo sinais e movimentos conjugados às intencionalidades.

Como metodologia foi realizada uma pesquisa em forma de diagnóstico pelos bolsistas do PIBID na escola Dom Joaquim Ferreira de Mello, das áreas Geografia, Historia, Letras, Educação Física, Artes Visuais, Biologia e Matemática em atividade na escola, com a aplicação de entrevistas preliminares direcionadas aos alunos para o desenvolvimento de um projeto a partir da demanda encontrada na instituição.

\section{Projeto e desenvolvimento}

Através dos dados obtidos no diagnóstico foi possível construir o projeto "O Corpo em Movimento - Esporte, Expressão corporal, Espaço e Saúde” buscando o aprendizado em ar livre, fora do espaço físico escolar, e oferecer a ampliação de possibilidades para o ensino e aprendizagem, de acordo com a principal demanda da escola.

O projeto interdisciplinar aplicou atividades desenvolvidas pelo Programa Institucional de Bolsa de Iniciação à Docência, com a turma do $6^{\circ}$ ano e também posteriormente com outras turmas do ensino fundamental da escola atendida. As atividades foram discutidas pelo grupo e embasadas em referencial bibliográfico. 

e-ISSN 2016/Atual: 2525-7870 | e-ISSN 2015/2016: 2447-018X

Os encontros foram divididos em três momentos: Café consciência, Circuito na Praça Dom Antônio Zattera e Análise da expressão corporal e minidiário.

O primeiro momento denominado de "Café consciência" (Figura 1) consistiu de um café composto por alimentos (confeccionados pelos pibidianos com preparo adequado), buscando introduzir a seguir, as demais atividades do projeto. A partir deste café aconteceu uma conversa sobre alimentação saudável, realizada antes da prática de esportes.

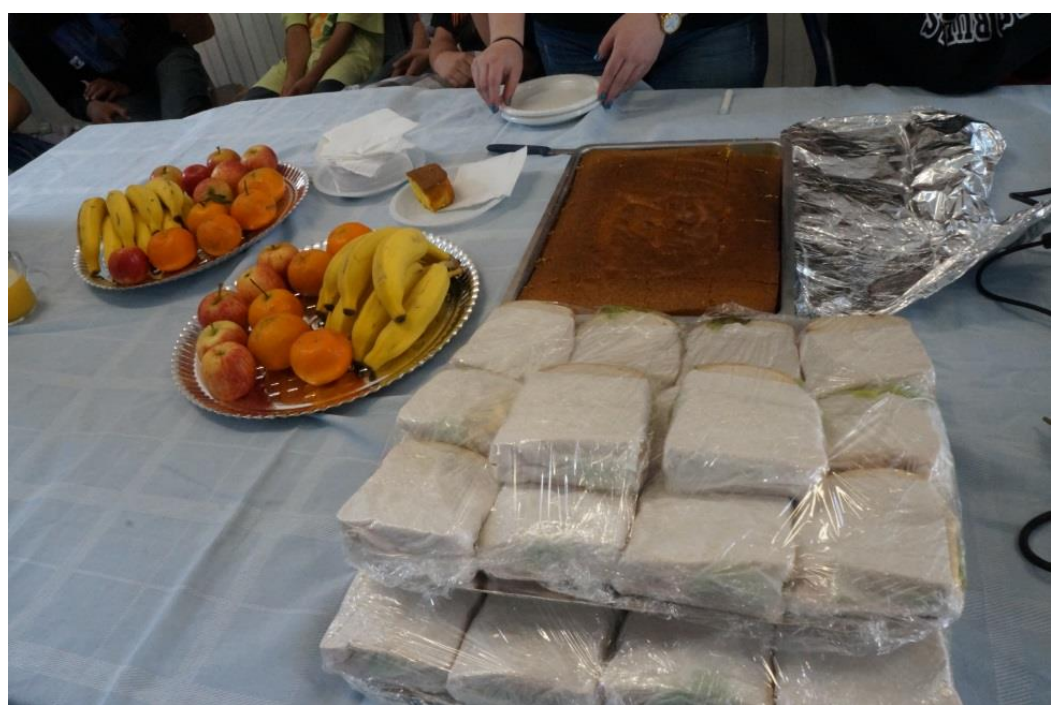

Figura 1: Foto do lanche servido aos alunos.

Nos Parâmetros Nacionais Curriculares (BRASIL, 1998) o tema alimentação saudável se enquadra no eixo temático Ser Humano e Saúde onde para o ensino fundamental para as séries finais, foca na recomendação de uma boa alimentação para a saúde e suas condições de vida e as de outras pessoas, bem como processos de saúde-doença.

No Circuito na Praça Dom Antônio Zattera, houve um deslocamento dos alunos para o local, onde aplicaram-se atividades envolvendo diferentes áreas de estudo e também contou com fotografias em forma de registros de cada momento do circuito.

A atividade física é um importante auxiliar para o aprimoramento e desenvolvimento do adolescente, nos seus aspectos morfofisiopsicológicos, podendo aperfeiçoar o potencial físico determinado pela herança e adestrar o indivíduo para um aproveitamento melhor de suas possibilidades (BARROS, 1993).

Uma das atividades escolhidas foi o Slackline, que é um esporte radical relativamente recente no Brasil. É desenvolvido a partir de uma fita elástica esticada entre dois pontos fixos, o que permite ao praticante andar e fazer manobras em sua extensão.

No caso de sua utilização em espaço escolar, não é considerado um esporte perigoso, pois a fita é estendida próxima ao chão, e os alunos são auxiliados pelos bolsistas, com o 
RELACult - Revista Latino-Americana de Estudos em Cultura e Sociedade

Revista Latinoamericana de Estudios en Cultura y Sociedad | Latin American Journal of Studies in Culture and Society V. 02, Ed. Especial, dezembro, 2016, p. 200-207| periodicos.claec.org e-ISSN 2016/Atual: 2525-7870 | e-ISSN 2015/2016: 2447-018X

objetivo de evitar machucaduras (Figura 2). "A base do esporte está em se equilibrar em uma fita de nylon estreita e muito flexível, que deve ter suas extremidades fixadas em árvores, postes e rochas. É uma ótima atividade para treinar equilíbrio, postura e concentração" (DESVIANTES, 2016).

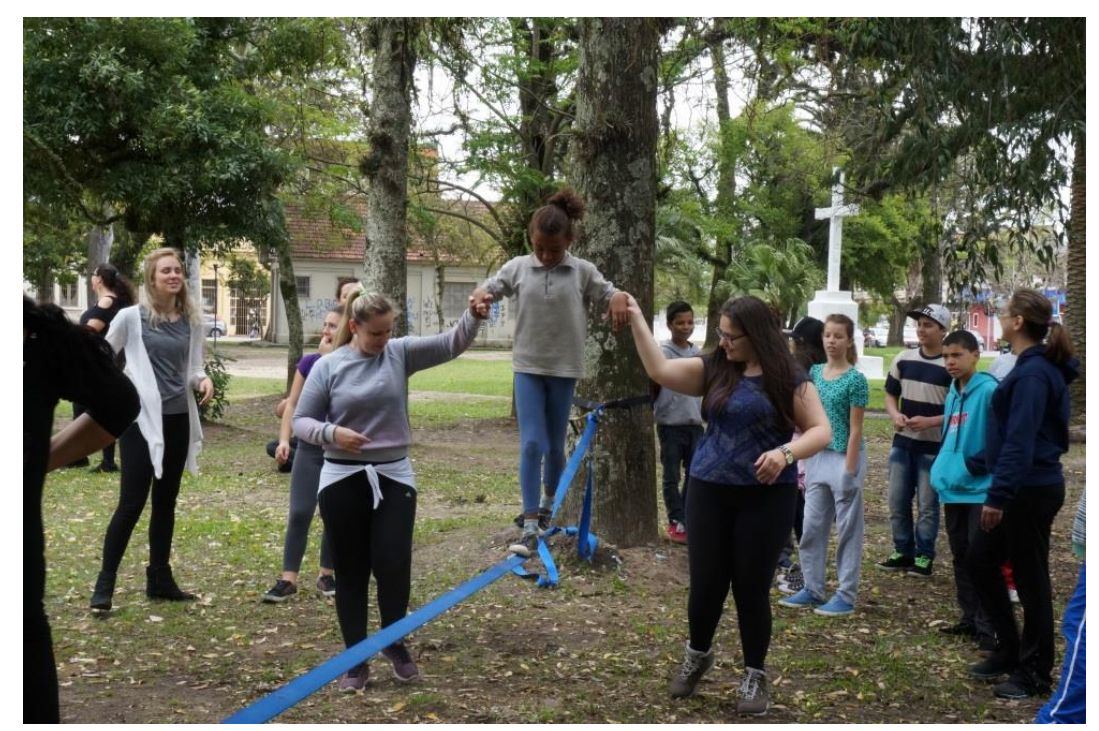

Figura 2: Aluna experimentando pela primeira vez o Slackline, com auxilio das bolsistas do Pibid.

Para Betrán e Betrán (1995), as atividades ao ar livre são caracterizadas por um conjunto de práticas recreativas, que estão na origem de novos hábitos e gostos. Podemos observar um aumento da busca do prazer e da liberdade, que a natureza pode proporcionar. Nascem diferentes formas de ver o desporto, onde o rendimento é desvalorizado (Figura 3).

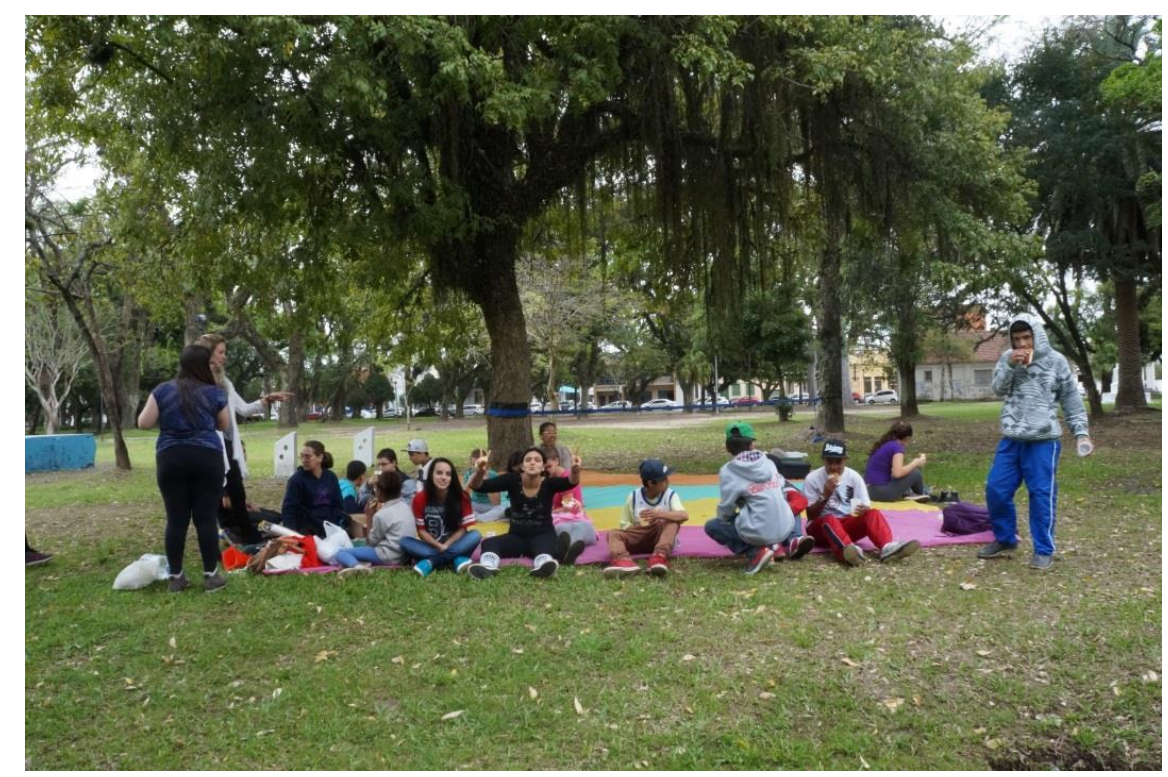

Figura 3: Alunos em atividade no Parque Dom Antônio Zattera. 
Com o objetivo de realizar a análise da expressão corporal foi feita uma roda de conversa e discussão das atividades realizadas na praça, com ênfase nas fotografias que relatavam diferentes momentos do passeio.

Para uma avaliação final, usou-se o minidiário, onde os alunos relataram suas experiências em relação às atividades que participaram com os pibidianos. Os minidiários buscaram registrar, em forma de textos discursivos, as principais impressões dos alunos a respeito do vivenciado na atividade. Na visão de Soares (2005, p.85), os “[...] diários podem revelar a relação do aluno com o conteúdo, com o professor ou outros colegas, com a metodologia, com experiências anteriores".

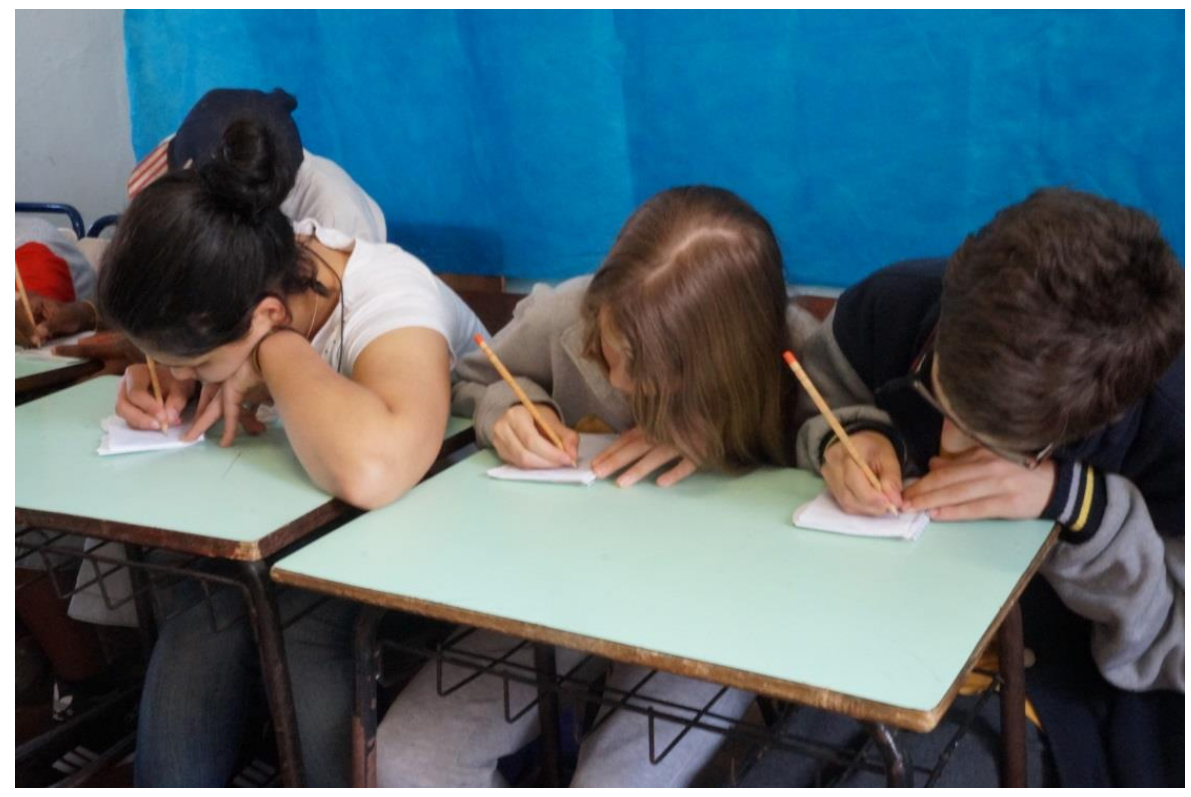

Figura 4: Atividade com o mini diário.

\section{Breves conclusões}

A partir de avaliações e auto avaliações realizadas pelos acadêmicos, supervisores e coordenadoras, constatou-se que a principal colaboração do PIBID foi o contato direto com a realidade escolar brasileira. Compreender esta realidade foi vivenciar as dificuldades na aplicação do projeto em função das paralisações dos professores estaduais, encarando a luta pela educação de forma direta. Conseguir conviver com os alunos e professores, e com suas respectivas carências, enquanto ocupantes desse espaço, é animador e desanimador, ao mesmo tempo. Entendeu-se, que é necessário uma árdua caminhada até conseguirmos uma educação, de fato, digna em nosso país, e na posição de profissionais da educação, precisamos estar conscientes das falhas sociais e dificuldades pessoais. Admitir essas falhas é pensar que 
não somos perfeitos e que estamos sempre caminhando e aprendendo, e que a autocrítica é importante na vivência do docente, do futuro professor e ser humano, político e consciente.

Alguns pontos falhos foram evidenciados pelos acadêmicos, muitos devido às mudanças de datas ocorridas e as consequentes dificuldades de organização em função de diversas atividades universitárias. Entenderam que o grupo, de forma integral, poderia ter se envolvido mais durante a realização do projeto, alguns acadêmicos assumiram de forma responsável as atividades e outros, por diversas situações, se esquivaram ou faltaram aos compromissos assumidos. Apesar das dificuldades encontradas na dinâmica escolar, os pibidianos compreenderam que houveram aprendizagens vivenciadas durante esse processo, e que estas promovem acréscimos para suas formações docentes. Entre elas, o conhecimento dos alunos e da rotina escolar. O contato maior e direto com os alunos aprimora a didática de trabalho; o contato direto com os professores e coordenação da escola faz obterem uma visão real de como é o cotidiano escolar, sua dinâmica e funcionamento.

Entendem que ainda é necessário aprender a trabalhar juntos e de forma interdisciplinar, salientando um ponto positivo - o trabalho com a adversidade - situação evidenciada no dia em que não foi possível ir à praça devido ao mau tempo.

Salientam, por vezes, a falta de colaboração dos colegas, no sentido de se comprometerem com as atividades práticas, comprometendo o funcionamento da aula prevista, pois a revisão do material a ser utilizado na aula e o tempo fizeram ocorrer diversos imprevistos, ocasionando deslizes na atuação docente.

O trabalho na EEEF Dom Joaquim teve prosseguimento em 2016, elencando novas temáticas e propiciando a participação dos alunos nessas escolhas. Encontramos dificuldades no tocante ao espaço físico, tanto para o desenvolvimento das atividades com os alunos como na realização de nossas reuniões no espaço da escola, e esperamos que isto possa ser resolvido. Assim, buscando aperfeiçoar as ações previstas, estaremos desenvolvendo atividades motivadoras com os alunos, propiciando o aprendizado e a alegria no espaço escolar, a partir da atuação do grupo PIBID - UFPel.

\section{Referências}

BARROS, R. et. al. O uso do tempo livre por adolescentes em uma comunidade metropolitana no Brasil. Adolesc. Latinoam., Porto Alegre, v.3, n.2, nov., 2002. Disponível em: http://raladolec.bvs/scielo.php Acesso em: 20 fev. 2015.

BETRÁN, J. O.; BETRÁN, M. U. La Crisis de la modernidad y la advenimento de la postmordenidad: el deport y las práticas físicas alternativas em él tempo de ócioactivo. Apunts Educatión Física Y Desportes, v.41, p.10-29, 1995. 

e-ISSN 2016/Atual: 2525-7870 | e-ISSN 2015/2016: 2447-018X

BRASIL. Ministério da Educação. Fundo Nacional do Desenvolvimento da Educação. Parâmetros Curriculares Nacionais: $3^{\circ}$ e $4^{\circ}$ ciclos do ensino Fundamental: saúde. Brasília, DF, 1998. Disponível em: http://http://portal.mec.gov.br/seb/arquivos/pdf/introducao.pdf Acesso em: 10 jun. 2015.

DESVIANTES. $\mathrm{O}$ que é Slackline e como começar. Disponível em: http://desviantes.com.br/blog/post/o-que-e-slackline-e-como-comecar-praticar/ Acesso em: 03 out. 2016.

SOARES, M. F. Diários escolares reflexivos como narrativas de experiências de aprendizagem. Contexturas: ensino crítico de língua inglesa. São Paulo, n. 8, p.79-90, 2005. 